\title{
Percurso da avaliação da educação superior nos Governos Lula'
}

Gladys Beatriz Barreyro"

José Carlos Rothen"II

I- Este texto, produto de pesquisa apoiada pela FAPESP, amplia e reelabora questões apresentadas no $25^{\circ}$ Simpósio Brasileiro e $2^{\circ}$ Congresso Ibero-Americano de Política e Administração da Educação: Políticas Públicas e Gestão da Educação: construção histórica, debates contemporâneos e perspectivas futuras, realizado em São Paulo, nos dias 26-30 de abril de 2011.

II- Universidade de São Paulo, São Paulo, SP, Brasil.

Contatos: gladysb@usp.br

III-Universidade Federal de São Carlos, São Carlos, SP, Brasil.

Contato: josecarlos@rothen.pro.br

\section{Resumo}

0 texto analisa a política de avaliação da educação superior desenvolvida durante os governos de Luiz Inácio Lula da Silva (2003-2010). Trata-se de uma pesquisa documental que utiliza a legislação e documentos oficiais do período como principal fonte de informação. 0 ponto de partida foi mostrar que o Sistema Nacional de Avaliação da Educação Superior (SINAES) implicou uma mudança na lógica da avaliação imperante. Para tanto, recupera-se o percurso da criação do SINAES, sua implantação e seus desdobramentos, distinguindo-se quatro fases: a) a proposta de uma nova política; b) a criação de legislação para alavancá-la; c) a implantação da lei; e d) a volta à lógica da política anterior (Provão), com a inclusão de índices. Conclui-se que o SINAES tentou empreender uma mudança na lógica de avaliação instituída desde o Provão, acrescentando três eixos na avaliação do sistema: a) a avaliação institucional com autoavaliação, em que se recupera o paradigma da avaliação formativa, b) a avaliação de cursos; e c) a avaliação dos estudantes, eliminando o Provão, mas criando uma prova em larga escala com outras características - o Exame Nacional de Desempenho dos Estudantes (ENADE). Contudo, em sua implantação, o SINAES sofreu profundas transformações a partir da criação do Conceito Preliminar de Cursos (CPC) e do Índice Geral de Cursos (IGC), que foram incorporados ao final do segundo Governo Lula. Os resultados do ENADE são seu componente de maior peso, mostrando que a lógica de regular o sistema pelos resultados de uma prova continua em vigor.

\section{Palavras-chave}

Avaliação da educação superior - Governo Lula - Política de educação superior - SINAES. 


\title{
The course of higher education evaluation in Lula governments'
}

\author{
Gladys Beatriz Barreyro" \\ José Carlos Rothen"II
}

I- This text, a product of research supported by FAPESP, extends and elaborates on issues presented at $25^{\circ}$ Simpósio Brasileiro e $2^{\circ}$ Congresso IberoAmericano de Política e Administração da Educação: Políticas Públicas e Gestão da Educação: construção histórica, debates contemporâneos e perspectivas futuras (25th Brazilian Symposium and 2nd Ibero-American Congress of Educational Policy and Administration: Public Policy and Management of Education - historic construction, contemporary debates and future prospects), held in São Paulo from 26 to 30 April 2011

II- Universidade de São Paulo, São Paulo, SP, Brazil.

Contact:gladysb@usp.br

III-Universidade Federal de São Carlos, São Carlos, SP, Brazil.

Contact:josecarlos@rothen.pro.br

\section{Abstract}

This article analyzes the policy of higher education evaluation developed during the governments of Luiz Inácio Lula da Silva (2003-2010). This is a documentary research which uses legislation and official documents of the period as its main sources of information. We began by showing that Sistema Nacional de Avaliação da Educação Superior (SINAES - National System of Higher Education Evaluation) brought about a change in the prevailing logic of evaluation. To do so, we recovered the course of the creation of SINAES, its implementation and consequences, distinguishing four phases: a) the proposal of a new policy, b) the creation of legislation to promote it, c) the implementation of the law and d) the return to the logic of the previous policy (Provão), with the inclusion of indexes. We have concluded that SINAES attempted to undertake a change in the evaluation logic established since Provão, adding three axes to the evaluation of the system: a) the institutional assessment with self-evaluation, which recovers the paradigm of formative assessment, $b$ ) the evaluation of courses and c) the evaluation of students, eliminating Provão but creating a large-scale test with other characteristics - Exame Nacional de Desempenho dos Estudantes (ENADE - National Examination of Student Performance). However, during its implementation, SINAES underwent major changes due to the creation of Conceito Preliminar de Cursos (CPC - Preliminary Concept of Courses) and Índice Geral de Cursos (IGC - General Index of Courses), which were added at the end of the second Lula government. The results of ENADE are the components with the largest weight in SINAES, showing that the logic of regulating the system by the results of a test is still in force.

\section{Keywords}

Higher education evaluation - Lula government - Higher education policy - SINAES. 


\section{Introdução}

Em meados da década de 1990, houve no Brasil uma reforma do Estado condizente com as concepções hegemônicas que, desde os anos 1980, tinham aparecido no mundo desenvolvido anglo-saxão como alternativa ao Estado de bem-estar social em crise. Em tais concepções "a defesa da livre economia de tradição liberal [coexistia] com a autoridade do Estado, de tradição conservadora" (AFONSO, 2005, p. 113).

Essa reforma do Estado propunha, entre outras coisas, a descentralização da execução de políticas e a diminuição da oferta direta pelo Estado de atividades que pudessem ser realizadas pelo setor privado. No setor educativo, a perda de poder estatal foi compensada com a criação do chamado Estado avaliador (NEAVE, 1988), isto é, a implantação de estratégias de avaliação centralizadas que assumiram, na maioria dos países, a forma de exames nacionais para verificação de desempenho.

No Brasil, no que concerne à educação superior - caracterizada pela estagnação do sistema, pela demanda reprimida e pelo baixo acesso da população a esse nível de ensino -, houve uma ampliação no número de vagas graças à expansão do setor privado, o que se deveu a mudanças na legislação que incentivaram sua participação. 0 crescimento de instituições privadas foi exponencial desde 1996, e o Exame Nacional de Cursos (ENC-Provão) foi idealizado como mecanismo de regulação estatal da educação superior pela via do mercado. ${ }^{1}$

A implantação do Provão esvaziou o Programa de Avaliação Institucional das Universidades Brasileiras (PAIUB), criado em 1993 pelo Ministério da Educação, mas gestado pela Associação Nacional dos Dirigentes das Instituições Federais de Ensino Superior (ANDIFES) após embates e experiências de avaliação - algumas traumáticas - durante a

1- Para maior detalhamento acerca desse processo, consultar: SILVA JÚNIOR; SGUISSARDI, 2001; CATANI; OLIVEIRA, 2000; CUNHA, 2003; DIAS SOBRINHO; RISTOFF, 2002; TRINDADE, 1999. década de 1980 (PARU, ${ }^{2}$ Comissão de Notáveis, GERES $^{3}$ e Lista dos improdutivos da $U_{S P^{4}}$ ).

O PAIUB e o Provão, nos anos de 1990, representaram dois paradigmas diferentes de avaliação: formativa e somativa. A primeira é aquela que é realizada ao longo do processo, com a participação dos atores, e que, de acordo com a concepção do PAIUB, deveria considerar toda a instituição, com a possibilidade de alcançar status emancipatório (DIAS SOBRINHO, 2000; SAUL, 1994). Já a avaliação somativa, que verifica os resultados alcançados ao final do processo (na concepção do Provão, aplicando um exame final aos alunos formandos), apresenta um viés regulatório devido à utilização dada aos seus resultados.

Se, por um lado, o Provão encontrou grande receptividade na imprensa nos momentos em que os resultados eram divulgados, pois a maioria das matérias apontava que esse exame seria um bom diagnóstico da educação superior, por outro, houve forte resistência do movimento estudantil e de acadêmicos vinculados às experiências anteriores de avaliação da educação superior, o que gerou algumas alterações pontuais, como a não inserção do resultado do exame no histórico escolar dos alunos e a previsão de avaliações in loco.

Em 2002, durante o programa de governo do então candidato Luiz Inácio Lula da Silva (Lula), intitulado Uma escola do tamanho do Brasil (COLIGAÇAO LULA PRESIDENTE, 2002), foram sinalizadas como metas algumas mudanças na avaliação, em sintonia com os princípios do PAIUB.

Este texto tem a finalidade de estudar, nos Governos Lula, o percurso da avaliação da educação superior como política pública, tendo por objetivo compreender seu significado. Para isso, são sintetizados resultados de pesquisa documental (legislação e documentos ofıciais) e bibliográfica (trabalhos acadêmicos publicados

2- Programa de Avaliação da Reforma Universitária

3- Grupo Executivo da Reforma do Ensino Superior

4- Lista de docentes da USP sem publicações entre 1985 e 1986, publicada pelo jornal Folha de S. Paulo, em 1988. 
sobre o período). Inicialmente, apresentaremos as características das políticas de educação superior nos referidos governos para, na sequência, estudar as políticas de avaliação.

\section{A educação superior nos Governos Lula}

Durante os dois governos de Luiz Inácio Lula da Silva (2003-2006 e 2007-2010), o Ministério da Educação (MEC) foi ocupado por três ministros, a saber, Cristovam Buarque, Tarso Genro e Fernando Haddad, diferentemente dos Governos FHC, em que Paulo Renato Souza permaneceu no cargo durante os oito anos. Tal característica influenciou o rumo das políticas de educação superior, que não foi uniforme durante os dois Governos Lula. Além disso, cabe ressaltar o apelo à consulta pública das propostas e/ou minutas de leis como uma prática recorrente ao longo das três gestões ministeriais, contrastando com a falta de diálogo entre o Ministério e a academia durante o governo anterior (BARREYRO, 2010).

Ainda, verificou-se a prevalência de um grupo ligado à Associação Nacional de Dirigentes das Instituições Federais de Ensino Superior (ANDIFES) nos cargos relacionados à educação superior. Passaram pela direção da Secretaria da Educação Superior (SESu): José Roberto Antunes dos Santos, Nelson Maculan e Ronaldo Mota - todos professores de instituições federais de educação superior (IFES). Em setembro de 2008, Mota foi substituido por Maria Paula Dallari, assessora jurídica do MEC, anteriormente professora da Universidade Católica de Santos e advogada da Universidade de São Paulo, rompendo, assim, a continuidade de professores das IFES.

Outro órgão que apresentou bastante rotatividade foi o Instituto Nacional de Estudos e Pesquisas Anísio Teixeira (Inep): Otaviano Helene (USP), Raimundo Luiz Araújo (exSecretário de Educação de Belém, PA, 19972002), Eliezer Pacheco (UNIJUI), Reynaldo Fernandes (USP) e José Joaquim Soares Neto
(UnB). Na diretoria responsável pela avaliação da educação superior, ocuparam o cargo: Raimundo Luiz Araújo, Dilvo Ristoff (UFSC), Iguatemy $M$. de Lucena Martins (UFPB) e Claudia Maffıni Griboski (UnB). ${ }^{5}$

A gestão de Buarque no campo da educação superior foi marcada pela discussão dos rumos da avaliação paralelamente à aprovação da lei de inovação que facilita

a utilização dos recursos - físicos, materiais e humanos - das universidades pelas empresas, assim como a transferência de tecnologia daquelas para estas. (SGUISSARDI, 2006, p. 1042)

Durante as gestões de Genro e Haddad, as políticas de educação superior desenvolvidas enfatizaram, principalmente, o acesso a esse nível de educação, sobretudo pela ampliação da rede federal de ensino e pela oferta de bolsas em instituições privadas; paralelamente, foram estimuladas políticas de ação afırmativa nas instituições federais.

A ampliação da rede federal de ensino aconteceu tanto pela via da criação de novas IFES - com a organização acadêmica de universidades ou de Institutos Federais de Educação, Ciência e Tecnológica (IFs) -, quanto pela expansão dos campi das universidades existentes e pela implantação do Programa de Reestruturação das Universidades Federais (REUNI), visando ao aumento das vagas em IFES. Também, foram criados cursos à distância pela Universidade Aberta do Brasil (UAB). ${ }^{6}$

A ampliação do setor privado de educação superior, que se iniciou no Governo FHC, teve continuidade. Se naquela gestão a ampliação havia se dado pela flexibilização normativa para

\footnotetext{
5- Inicialmente, a Diretoria de Estatísticas e Avaliação da Educação Superior era responsável pela avaliação; a partir de sua divisão em duas pelo Decreto n 6.317/2007 (BRASIL, 2007b), a responsabilidade passou para a Diretoria de Avaliação da Educação Superior (DAES).

6- A Universidade Aberta do Brasil é um sistema composto por universidades públicas, financiado com recursos do MEC e que oferece cursos superiores à distância para público em geral. Os professores atuantes na educação básica têm prioridade, assim outros profissionais de educação básica (CAPES, s.d.).
} 
a abertura de novos cursos e IES, no Governo Lula, a expansão foi decorrente de uma política social: o Programa Universidade para Todos (Prouni), no qual instituições privadas, com ou sem fins lucrativos, oferecem bolsas de estudo totais ou parciais a alunos de baixa renda, em troca de isenções fiscais. ${ }^{7}$

Houve também a tentativa de criação de uma lei de educação superior (Reforma Universitária). A partir da elaboração de um projeto de lei submetido à Consulta Pública e após várias mudanças importantes na minuta original, uma nova proposta foi enviada ao Congresso. Polêmico, tal projeto recebeu centenas de emendas e não foi tratado no plenário, tendo sua discussão finalizada ao ser apensado ao projeto de lei $n^{\circ} 4.212 / 2004$, que tramitava na Câmera dos Deputados desde 2004.

\section{A avaliação da educação superior nos Governos Lula}

A avaliação da educação superior durante os Governos Lula teve um percurso conturbado, no qual distinguimos quatro fases: a) a proposta de uma nova política; b) a criação de legislação para alavancá-la; c) a implantação da lei; e d) a volta à lógica da política anterior (Provão).

\section{Da proposta}

Em 2003 foi criada a Comissão Especial de Avaliação (CEA), com o objetivo de elaborar uma proposta de avaliação da educação superior em vista das críticas feitas no programa de governo de Lula ao modelo adotado pelo governo anterior. A Comissão foi composta, principalmente, por acadêmicos ligados às instituições públicas e, particularmente, ao PAIUB.

Durante a realização dos trabalhos da Comissão, ocorreram debates na imprensa sobre a validade ou não do Exame Nacional de Cursos, o Provão. 0 Ministro Buarque, engrossando o coro de membros do governo anterior, defendeu

\section{7- Sobre o PROUNI, ver CARVALHO, 2011, entre outros}

a realização do exame e, ainda, relativizou na imprensa o trabalho da Comissão ao ressaltar sua convicção de que a nova proposta consistiria em um aperfeiçoamento do Provão, e não em sua total substituição. A Comissão apresentou ao Ministro Buarque, em setembro de 2003, a proposta do Sistema Nacional de Avaliação da Educação Superior (SINAES) (BRASIL, 2004b). A proposta, inspirada nos princípios emancipatórios do PAIUB, estava baseada na centralidade da avaliação institucional, processo que se iniciaria com a autoavaliação. Sem ignorar o apelo que a sociedade brasileira tem por exames em larga escala, mas diminuindo a ênfase dada no Governo FHC, a proposta incluía uma prova que deveria ser aplicada a uma amostra dos alunos ingressantes e concluintes por áreas de conhecimento, sendo realizada apenas uma vez a cada três anos. Dessa forma, diferentemente do Provão, os alunos seriam avaliados por grandes áreas de conhecimento, e não mais por cursos (ROTHEN; BARREYRO, 2011).

Após embates nos bastidores do MEC, o Ministro Buarque propôs, num documento substitutivo ao da Comissão, a criação de um Índice de Desenvolvimento do Ensino Superior (IDES), com o objetivo de aferir a qualidade do ensino, da aprendizagem, da infraestrutura e da responsabilidade social das instituições de educação superior (BRASIL, 2003a).

Finalmente, em dezembro de 2003, foi editada a Medida Provisória $n^{0} 147 / 2003$, instituindo o Sistema Nacional de Avaliação e Progresso do Ensino Superior (SINAPES). 0 SINAPES, segundo a redação do documento, tinha a finalidade de

avaliar a capacidade institucional, o processo de ensino e produção do conhecimento, o processo de aprendizagem e a responsabilidade social das instituições de ensino superior avaliadas. (BRASIL, 2003b)

Ele previa a criação de duas agências: a Comissão Nacional de Orientação da Avaliação 
(CONAV) e a Comissão Nacional de Avaliação e Progresso do Ensino Superior (CONAPES), com funções, respectivamente, executivas e de consulta. Além disso, propunha o estabelecimento de Comissões Próprias de Avaliação (CPAs) em cada IES, deixando para regulamentação pelo MEC a definição dos procedimentos de avaliação do Sistema. Não havia qualquer menção a uma prova; inclusive, a medida provisória revogava os artigos da Lei ${ }^{0}$ 9131/1995, que fundamentaram a existência do Provão.

Tal período, que aqui denominamos Da proposta, iniciou-se com uma postura democrática, trazendo à discussão a questão da avaliação por meio de consultas públicas e debates na imprensa. A medida provisória que instituiu o SINAPES não respeitou o processo de debate, chegando a ponto de ignorar a proposta apresentada pelo próprio Ministério.

\section{Da legislação}

Com a reforma ministerial de 2004, Cristovam Buarque foi substituído por Tarso Genro. Logo a seguir, no Congresso Nacional, foi votado o projeto de conversão da medida provisória em lei, que recuperou algumas das propostas da CEA e foi promulgado como Lei $\mathrm{n}^{0} 10.861 / 2004$ (BRASIL, 2004e). Dessa forma, instituiu-se o SINAES, coordenado e supervisionado por um órgão colegiado especialmente criado para esse fim, a Comissão Nacional de Avaliação da Educação Superior (CONAES).

Houve, assim, dois SINAES: o da proposta da Comissão Especial de Avaliação e o estabelecido em lei. 0 segundo recuperou apenas parcialmente os princípios emancipatórios da primeira proposta, conciliando-o com a visão regulatória proveniente da época do Provão. No período da implantação, foi permanente a tensão entre essas duas visões.

$$
0 \text { SINAES da Lei } n^{\circ} \quad 10.861 / 2004
$$
estabeleceu: a avaliação institucional, composta por autoavaliação e avaliação externa; a avaliação de cursos, consistindo das visitas in loco de avaliadores externos; e a avaliação dos estudantes, pelo Exame Nacional de Desempenho dos Estudantes (ENADE) (BRASIL, 2004e). Para o desenvolvimento da autoavaliação, a lei estabeleceu a criação de Comissões Próprias de Avaliação (CPAs) em cada IES, as quais teriam atuação autônoma na instituição visando coordenar o processo.

\section{Da implantação}

Alguns membros da CEA posteriormente ocuparam cargos-chave na implantação do SINAES, tais como Hélgio Trindade e José Dias Sobrinho, professores de instituições públicas de educação superior que foram membros da CONAES. No Inep, que concentrava as atividades de execução das avaliações no novo sistema, Dilvo Ristoff, como já dito, assumiu a Diretoria de Estatísticas e Avaliação da Educação Superior, diretamente encarregada da implantação do SINAES.

Nesse período foram desenvolvidas ações de orientação dos processos de autoavaliação institucional. Inicialmente, a CONAES divulgou as Diretrizes para a Avaliação das Instituições de Educação Superior (BRASIL, 2004d) e o Roteiro de Autoavaliação Institucional (BRASIL, 2004c), os quais apresentaram uma concepção de avaliação institucional formativa, apelando para a participação da comunidade no processo de autoavaliação. Foi estabelecido, também, um calendário com datas para cada etapa (BRASIL, 2005b). Começaria assim o ciclo avaliativo, composto pela autoavaliação institucional da qual derivaria um relatório elaborado por cada Comissão Própria de Avaliação (CPA); depois haveria a avaliação institucional externa, por meio da visita de avaliadores institucionais. Após esse ciclo teria início o processo de regulação.

Além disso, foram realizados quatro seminários de divulgação do SINAES em diversas regiões e se acompanhou o processo de criação das CPAs, solicitando seu cadastro no Inep. Assim, no final do ano de 2004, haviam sido cadastradas 1.831 Comissões no Inep (ALMEIDA JÚNIOR, 2005). Essas ações mostraram a 
valorização da autoavaliação institucional como processo prévio à avaliação institucional externa.

A implantação do SINAES nas instituições e o resultado do trabalho das CPAs podem ser avaliados pela leitura de alguns estudos de caso apresentados em artigos, teses e dissertações. Em um trabalho que analisa os artigos sobre o SINAES publicados na Revista Avaliação (ROTHEN; BARREYRO, 2010), mostra-se que a maioria desses textos é resultado de pesquisas realizadas na instituição em que os autores desempenham suas funções, muitas vezes como membros de CPAs.

Os estudos evidenciam processos institucionais com ênfases variadas. Alguns casos demonstram que a autoavaliação prevista no SINAES consistiu em uma continuação de experiências já iniciadas pelas instituições (CARBONARI, 2006); outros indicam uma continuidade de algo iniciado com o PAIUB (BOTH, 2005). Vários trabalhos assinalam o problema da falta de participação da comunidade acadêmica nas diversas fases da autoavaliação (ANDRIOLA; SOUZA, 2010), inclusive quando ela é on-line (POLIDORI; FONSECA; LARROSI, 2007). Alguns artigos discutem o trabalho realizado pelas CPAs e assinalam que elas elaboram o projeto de autoavaliação utilizando dados qualitativos, quantitativos e, em certos casos, documentos da instituição (AUGUSTO; BALZAN, 2007).

Pesquisa realizada com 899 CPAs de instituições com até 500 alunos (que são 50\% das IES do país) mostra que as CPAs foram efetivamente constituídas, mas que apenas cumpriam burocraticamente a legislação, produzindo relatórios para o Inep conforme as orientações do SINAES. Esses relatórios eram descritivos, incorporando documentos e informações, mas não conseguiam realizar análises críticas da instituição. Em IES maiores e que já desenvolviam atividades de autoavaliação institucional anteriormente, a autora verificou processos de ampliação da participação (LEITE, 2008).

Em publicação do Inep (2011) foram analisados 172 relatórios de autoavaliação, produzidos por CPAs de diferentes tipos de instituições, entre 2004 e 2008: apenas 12,2\% consideraram, nesse processo de autoavaliação, todas as dimensões propostas pelo SINAES; mais de 50\% somente apresentavam gráficos e tabelas, sem a devida análise e interpretação ou mesmo sem informações; 61\% afirmavam terem feito sugestões de melhorias à instituição e não apenas escrito um relatório de autoavaliação; $25,5 \%$ mencionavam que haviam se efetivado as mudanças sugeridas, enquanto $74,5 \%$ dos relatórios assinalam não ter evidências dessas mudanças. Ainda, as universidades têm sido as que apresentaram relatórios mais completos, seguidas dos centros universitários e das faculdades, sendo que as universidades públicas levaram uma leve vantagem (BRASIL, 2011b).

Em síntese, os estudos mencionados evidenciam que as CPAs foram implantadas nas instituições de ensino superior e que os processos de autoavaliação produziram relatórios com graus diversos de aprofundamento. Na grande maioria das CPAs, o trabalho consistiu em apenas elaborar um documento para ser enviado ao Inep.

Quanto à avaliação externa, a CONAES emitiu um Instrumento de Avaliação Externa de Instituições em que privilegiou os efeitos regulatórios da avaliação (BRASIL, 2005a). Também divulgou nesse documento um calendário que indicava, a partir de agosto de 2005, os prazos para recredenciamento de instituições segundo a organização acadêmica de cada uma (BRASIL, 2005b). 0 calendário não foi cumprido pelo próprio Ministério e as visitas in loco para recredenciamento só começaram em 2009, após novo calendário divulgado em 2008.

Nesse intervalo, em 2006, houve a criação de um banco de avaliadores (BASIS) para o recrutamento de professores que fariam as avaliações externas de instituições e cursos. Os interessados que cumprissem os requisitos estabelecidos poderiam se inscrever on-line. Foram também organizados e ministrados cursos de capacitação para essas pessoas. Tal processo, aberto à comunidade, é entendido por Peixoto (2011) como um dos motivos do atraso na realização das avaliações externas. 
O Instrumento de Avaliação Institucional Externa foi revogado e substituído em outubro de 2008. Posteriormente teve uma nova revisão, em setembro de 2010, embora tenha recebido críticas pela não definição de "condições mínimas de qualidade" em que

percebe-se e se ratifica a subjetividade do processo no uso excessivo de advérbios e adjetivos, fragilizando, consideravelmente, a composição final do conceito do processo avaliativo. (POLIDORI et al., 2011, p. 272)

No que diz respeito à avaliação dos estudantes, o ENADE, uma prova em larga escala, teve sua primeira ocorrência em 2004. Nas primeiras edições, a avaliação foi aplicada aos alunos concluintes, tal como no Provão, mas inovava ao ser também aplicada aos alunos ingressantes. Outra diferença consistia em seu caráter amostral e não mais censitário. A aplicação da mesma prova aos concluintes e aos ingressantes visava medir o valor agregado que o curso/instituição fornecia ao aluno.

0 ENADE divide-se em duas partes: 10 questões de formação geral e 30 de conhecimento específico. Diferentemente do Provão, a quantidade de suas questões segue um padrão único para todas as áreas. Seus resultados são sistematizados no Conceito ENADE, o qual é organizado em uma escala de cinco níveis. Em 2005, criou-se o Indicador de Diferença entre os Desempenhos Observado e Esperado (IDD); com esse indicador, busca-se verificar quanto conhecimento a instituição forneceu aos seus alunos (valor agregado), tentando, dessa forma, superar o argumento - mormente defendido pelo setor privado da educação superior, desde o Provão - de que algumas instituições têm bom desempenho na prova por receberem bons alunos. Com esse indicador, cursos nos quais o desempenho dos ingressantes é próximo ao dos concluintes tem uma má avaliação, ao passo que são bem-avaliados aqueles em que o desempenho dos concluintes é superior ao dos ingressantes (ROTHEN; BARREYRO; 2011).
Embora o ENADE continuasse tendo destaque no sistema de avaliação e apresentando resultados simplificados que permitiam um ranque, a divulgação de seus resultados não teve tanto impacto nesses anos quanto teve o Provão, devido à perda de centralidade da avaliação entre as políticas ministeriais.

Durante o primeiro Governo Lula, na avaliação da educação superior, viuse agravado o represamento de processos de credenciamento de instituições e reconhecimento de cursos. Isso foi causado por duas razões: a) o questionamento das taxas pagas pelas IES para a realização desses processos pelo Inep; e b) o veto do Tribunal de Contas da União ao pagamento de pro labore aos professores de instituições públicas com dedicação exclusiva que faziam visitas de avaliação in loco. Tais questões exigiram medidas legais para serem resolvidas e para que o processo tivesse continuidade. Além disso, o ciclo do SINAES teve morosidade, o que levou à edição de diversas portarias para reconhecimento provisório dos cursos, devido à necessidade de emissão de diplomas aos formados (ROTHEN; BARREYRO, 2011).

Ao final do primeiro Governo Lula, em 2006, houve a edição de um decreto chamado de Decreto Ponte,,$^{8}$ em que foram defınidos os procedimentos de supervisão, regulação e avaliação da educação superior, bem como as atribuições entre diversos órgãos governamentais. Na prática, porém,

a Avaliação, ao invés de "referencial básico" aos processos regulatórios, vem se tornando "determinante" aos mesmos, criando equivalência entre avaliação e regulação, ou entre avaliação e controle, sem que as autoridades recorram a outros meios de convencimento, ou fomentem o "processo regular de avaliação", recomendado pela LDB. (FERNANDES, 2010, p. 59)

8- Decreto $n^{0} 5.773 / 2006$ (BRASIL, 2006). 


\section{Do retorno}

No segundo Governo Lula, apesar da permanência do Ministro Haddad, a avaliação da educação sofreu significativas mudanças, principalmente com o Plano de Desenvolvimento da Educação (PDE). Um dos pontos principais desse plano foi o Índice de Desenvolvimento da Educação Básica (IDEB), ${ }^{9}$ que relaciona o desempenho dos estudantes em exames padronizados (Prova Brasil/ SAEB) e a taxa média de aprovação. Por meio do IDEB pretende-se monitorar o desenvolvimento da educação e adotar uma visão gerencial, predefınindo metas para serem atingidas (ROTHEN, BARREYRO, 2011).

Quanto à avaliação da educação superior, apareceram mudanças significativas em relação ao período 2003-2006. Uma delas foi o desenvolvimento da função de fiscalização exercida pelo MEC. 0 mencionado Decreto Ponte foi um marco, por ter explicitado as funções de avaliação e de regulação e por ter definido a de supervisão do sistema, o que enfatizou a fiscalização.

0 exercício da função de supervisão do sistema centrou-se na utilização dos resultados do ENADE como balizadores para a realização de visitas in loco por especialistas. Para tanto, em dezembro de 2007 foi editada a Portaria Normativa $\mathrm{n}^{\circ} 40$ em que se anunciou a atribuição de um conceito preliminar que seria aplicado para a renovação de reconhecimento de cursos (BRASIL, 2007a). Na prática, esse foi o primeiro anúncio do que aconteceria em 2008: a criação do Conceito Preliminar de Cursos (ROTHEN; BARREYRO, 2011).

0 conceito preliminar previsto na Portaria seria composto pelos resultados do ENADE, por dados do Censo da Educação Superior e por outros dados de cadastros do MEC. Segundo a Portaria (art. $35^{\circ}, \S 1^{\circ}$ ), caso o conceito preliminar fosse satisfatório, a avaliação in loco poderia ser evitada. Contudo, na lei do SINAES, a avaliação de cursos in loco é obrigatória:

9- 0 IDEB foi instituído pelo Decreto nº 6.094/2007 (BRASIL, 2007c).
[...] a avaliação dos cursos de graduação utilizará procedimentos e instrumentos diversificados, dentre os quais obrigatoriamente as visitas por comissões de especialistas das respectivas áreas de conhecimento. (BRASIL, 2004e, art. $4^{\circ}, \S 1^{\circ}$, grifo nosso)

Assim, a lei do SINAES sancionada no primeiro Governo Lula foi desrespeitada por ato normativo de menor hierarquia jurídica: uma portaria.

Em 2008, na área de Direito, 60 cursos que obtiveram nota 1 ou 2 foram visitados, 23 assinaram protocolos de saneamento de deficiências (PORTAL MEC, 2007) e, como consequência do processo de supervisão, foram cortadas 24.380 das 45.042 vagas oferecidas pelos cursos supervisionados (PORTAL MEC, 2008b). Concomitantemente, novos requisitos para a abertura de cursos de Direito foram criados, assim como um novo instrumento específico para esses cursos, iniciando-se um processo de diferenciação dos instrumentos de avaliação externa de cursos.

Também foram aplicados procedimentos de supervisão a 17 cursos de Medicina que passaram por visitas in loco, assinatura de termo de saneamento de deficiências e medidas cautelares, chegando, no final do processo, à suspensão de vestibulares e/ou ao corte do número de vagas oferecidas (PORTAL MEC, 2008a; PINHO, 2008).

Em 2009, 60 cursos de Pedagogia passaram por processos de supervisão que incluíram visitas in loco por comissão de especialistas instituída para esse fim e assinatura de termo de saneamento de deficiências. Após o término do processo, sete cursos foram fechados (BRASIL, 2009a).

Até setembro de 2009, 123 IES (universidades e centros universitários) haviam sido supervisionadas devido ao não cumprimento do mínimo de professores titulados e/ou do vínculo empregatício de seus docentes, sendo necessário, nesses casos, um termo de saneamento de deficiências e medidas cautelares para suspensão de criação de cursos e vagas (BRASIL, 2009b). 
Esses processos de supervisão levaram ao fechamento de cursos e instituições em 2010, bem como à criação de normas mais rígidas para a expansão de instituições, segundo os resultados obtidos.

No apagar das luzes do Governo Lula, em outubro de 2010, o Conselho Nacional de Educação emitiu a Resolução n 3/2010, que estabeleceu normas e procedimentos para credenciamento e recredenciamento de universidades (BRASIL, 2010a). Essa determinação incorporou mais requisitos aos já estabelecidos pela legislação anterior (LDB e Decreto Ponte), incluindo a necessidade de que o credenciamento de universidades derive de centros universitários com 9 anos de existência ou, em casos justificados, de faculdades com 12 anos de existência. Os resultados de avaliações são alguns desses requisitos, como a necessidade de a instituição ter obtido conceito igual ou superior a 4, tanto no conceito institucional quanto no Índice Geral de Cursos. Ainda, as instituições devem ter 60\% de seus cursos reconhecidos ou em processo de reconhecimento, e oferecer regulamente quatro cursos de mestrado e dois de doutorado. Também é considerada a atuação da instituição quanto à resolução de problemas apontados pela CPA da instituição e são levados em conta processos de supervisão, que não poderão incluir mais de $20 \%$ de seus cursos. Para o recredenciamento de universidades, elas deverão ter obtido conceito igual ou superior a 3 no IGC (BRASIL, 2010a). Além de estabelecer critérios mais exigentes, a norma incluiu os resultados das avaliações como requisitos para credenciamento e recredenciamento de IES.

A despeito das ações regulatórias anteriormente descritas, que pela primeira vez na avaliação da educação superior chegaram a ter consequências como o fechamento de instituições ou o corte de vagas, o tom do segundo Governo Lula no que diz respeito à avaliação foi a retomada da tendência quantitativista e o retorno dos ranques, como será mostrado a seguir.
Em agosto de $2008^{10}$ foi criado o Conceito Preliminar de Cursos (CPC), composto pelos resultados do ENADE e por insumos "com influência na qualidade dos cursos", tais como qualificação docente, regime de trabalho, planejamento do ensino e infraestrutura (BRASIL, 2008c). Algumas dessas informações são obtidas junto ao cadastro de docentes do INEP e outras extraídas das respostas dos alunos ao questionário socioeconômico do ENADE.

Diferentemente da prática estabelecida pelo MEC quanto a outras políticas (SINAES, PROUNI, Reforma Universitária), que foram divulgadas previamente e dispostas para consulta pública, a instituição do CPC foi realizada por portaria, como se fosse apenas uma questão operacional decorrente da implementação do SINAES, e não uma mudança central que retoma velhas concepções e discussões sobre os modelos de avaliação da educação superior no país. A emergência dos índices surpreendeu a gregos e troianos, gerando inúmeras críticas, seja por questionamentos técnicos na construção do indicador, ${ }^{11}$ seja pela descaracterização do SINAES. ${ }^{12}$ Poucas vozes defenderam a nova proposta. ${ }^{13}$

0 Conceito mudou a implementação do SINAES, limitando as visitas in loco aos cursos que obtiveram um conceito preliminar menor que $3,{ }^{14}$ o que gerou a diminuição de 3.000 visitas previstas por ano para 1.800. Tal motivo, embora louvável no ponto de vista administrativo, não o é para o objetivo de melhoria de qualidade, pois, ao se aligeirar os processos de avaliação de cursos, perdeu-se o caráter formativo da avaliação. Parece que apenas interessa fazer uma operação limpa lixo, como disse Eunice Durham (2008) a respeito

\section{0- Portaria Normativa $n^{\circ} 4 / 2008$ (BRASIL, 2008a).}

11- Ver CASTRO, 2008; SCHWARTZMAN, 2008; BARREYRO, 2008; ROTHEN; BARREYRO, 2009

12- Ver DIAS SOBRINHO, 2008; LEITE, 2008; GIOLO, 2008; LIMANA, 2008; BARREYRO, 2008, POLIDORI, 2009.

13- Ver VERHINE, 2008; BITTENCOURT; CASARTELLI; RODRIGUES, 2009.

14- Os processos de renovação de reconhecimento dos cursos que obtivessem conceito 5 seriam renovados por Portaria; os que obtivessem 4 ou 3 poderiam pedir avaliação in loco para mudar seu conceito (Portaria Normativa $n^{\circ} 4 / 2008$; Art. $2^{\circ}, \S 3^{\circ}$ e $\S 4^{\circ}$ ). 
do Provão, ou seja, focalizar naquilo que está muito ruim, o que é importante, mas não constitui um processo de melhoria de qualidade, afinal, dispensando-se visitas para os cursos que apresentam a nota mínima aceitável (3) e também para os bons e excelentes (4 e 5), sinaliza-se conformidade e acomodação.

A criação do Índice Geral de Cursos (IGC), em setembro de $2008,{ }^{15}$ consolidou a influência na educação superior da tendência internacional de uso de indicadores. 0 novo índice foi composto pelas médias ponderadas dos CPCs e das notas dos programas de pósgraduação das IES avaliados pela CAPES. Alguns dos questionamentos ao IGC aconteceram pelo fato de os CPCs utilizarem resultados do ENADE que não permitiam comparação entre cursos de áreas diversas (e nem do mesmo curso em diferentes $\operatorname{anos}^{16}$ ) e pelo fato de a avaliação de insumos estar fundamentada na opinião do corpo discente. Além disso, pressupõe-se que uma instituição é a somatória de seus cursos.

0 Índice tem sido divulgado pelo MEC na forma de ranque de instituições, tendo sido em 2008 a única vez em que isso foi feito por um órgão governamental. Antes - no Governo FHC - e depois, o mesmo foi feito pela mídia, e não pelo MEC.

O CPC sofreu mudanças em 2009, atendendo algumas das críticas realizadas. Os resultados do ENADE perderam peso, assim como a opinião dos estudantes; por sua vez, aumentou-se o peso da titulação de doutores. Ainda, em 2009, o Ministério deixou de fazer ranques, voltando à prática de apenas oferecer os dados para que eles fossem informados à imprensa e aos departamentos de marketing das IES. Contudo, a mudança mais importante foi que o ENADE deixou de ser amostral para ser censitário, tal como era o Provão. Essa mudança foi explicada devido a uma diferença de concepção entre a proposta da CEA e a

15- Portaria Normativa $n^{0}$ 12/2008 (BRASIL, 2008b).

16- A prova do ENADE não permite comparações, diferentemente da prova do ENEM, que se utiliza da Teoria de Resposta ao Item e permite comparações entre provas de diferentes anos. subjacente aos atuais índices. A utilização de uma amostra, conforme proposto pela CEA em 2004, não é problemática, pois se compreendia que a prova seria apenas um instrumento para diagnóstico do estado da educação superior. Porém, no momento em que o ENADE foi caracterizado como um instrumento para classificação e regulação, as instituições sentiram que a adoção de amostras podia alterar o posicionamento institucional no ranque, ou seja: as amostras permitem certa confiabilidade para conhecer a realidade da educação superior, enquanto o ranque pode gerar desconfianças.

Ao final do Governo Lula, novas mudanças continuaram a transformação: em dezembro de 2010, houve a republicação da Portaria $n^{\circ} 40$ que havia sido editada em 2007, incluindo novidades nos processos de avaliação. No que diz respeito ao ENADE, tal republicação estabeleceu que a prova teria duas partes, “uma prova geral de conhecimentos e uma prova específica de cada área", diferentemente do estabelecido pelo SINAES, que determinava que o $\operatorname{ENADE}^{17}$ teria uma prova de formação geral e uma prova de conteúdos programáticos previstos nas diretrizes curriculares de cada curso. Vale ressaltar que a prova de formação geral, que pretendia aferir "as competências para compreender temas exteriores ao âmbito específico de sua profissão, ligados à realidade brasileira e mundial e a outras áreas do conhecimento" (BRASIL, 2004e), na redação da lei do SINAES passou para "uma prova geral de conhecimentos" (ou seria uma prova de conhecimentos gerais?). Note-se ainda que "os conteúdos programáticos [...] do curso de graduação" do SINAES foram transformados em "uma prova específica de cada área" (ou seria uma prova específica de cada curso?).

A Portaria $n^{\circ} 40$, versão 2010, trouxe ainda a novidade de que os estudantes

\footnotetext{
17- "O ENADE aferirá o desempenho dos estudantes em relação aos conteúdos programáticos previstos nas diretrizes curriculares do respectivo curso de graduação, suas habilidades para 0 ajustamento às exigências decorrentes da evolução do conhecimento, e suas competências para compreender temas exteriores ao âmbito específico de sua profissão, ligados à realidade brasileira e mundial e a outras áreas do conhecimento" (BRASIL, 2004e).
} 
ingressantes não mais fariam a prova específica, mas apenas a prova geral, a qual, a partir desse momento, passaria a ser realizada "com base na matriz de referência do Exame Nacional do Ensino Médio (ENEM)”. Ou seja, das "competências para compreender temas exteriores ao âmbito específico de sua profissão, ligados à realidade brasileira e mundial e a outras áreas do conhecimento", passa-se a considerar as competências adquiridas no ensino médio. 0 ENADE postulado pelo SINAES não cogitava auferir os conhecimentos obtidos no ensino médio, mas sim o valor agregado do curso.

Outra inovação da Portaria: os ingressantes que tiverem realizado o ENEM não precisarão fazer a prova geral do ENADE. Ora, o ENEM e o ENADE são provas diferentes, com objetivos diferentes. 0 ENEM é uma prova realizada seguindo a Teoria de Resposta ao Item e o ENADE não, ou seja, os resultados do primeiro podem ser comparados de um ano para outro, enquanto o mesmo não pode ser feito com o segundo. Dessa forma, seria criada uma diferença, no interior do ENADE, entre resultados comparáveis e não comparáveis.

Em síntese, do ENADE inicial fica apenas a prova de conhecimentos específicos (denominada prova especifica na Portaria), pois a prova geral será um ENEM-ADE, (ENADE com a matriz do ENEM). No entanto, como prova de conhecimentos específicos já era o ENC-Provão, percebe-se também nessa nova mudança o retorno do Provão: uma prova de conhecimentos específicos aplicada a todos os alunos concluintes dos cursos avaliados. ${ }^{18}$

Quadro 1 - Transformações ENC-Provão/ENADE: vigência de conceitos e índices

\begin{tabular}{|c|c|c|c|c|c|}
\hline $\begin{array}{l}\text { Características } \\
\text { Prova/Ano }\end{array}$ & $\begin{array}{l}\text { ENC-Provão } \\
1996 \text { a } 2003\end{array}$ & $\begin{array}{c}\text { ENADE } \\
2004 \text { a } 2007\end{array}$ & $\begin{array}{c}\text { ENADE } \\
2008 \text { e } 2009\end{array}$ & $\begin{array}{l}\text { ENADE } \\
2010\end{array}$ & $\begin{array}{l}\text { ENADE a partir de Portaria } \\
\text { n } 40 / 2007 \text { (rep. 2010) }\end{array}$ \\
\hline Ingressantes & & $x$ & $x$ & $x$ & \\
\hline Concluintes & $x$ & $x$ & $x$ & $x$ & $x$ \\
\hline Amostral & & $x$ & $x$ & & \\
\hline Censitária & $x$ & & & $x$ & $x$ \\
\hline Índices & & & $\mathrm{CPC} / \mathrm{IGC}$ & $\mathrm{CPC} / \mathrm{IGC}$ & $\mathrm{CPC} / \mathrm{IGC}$ \\
\hline
\end{tabular}

Fonte: Elaboração própria.

\section{Considerações finais}

Nos Governos Lula, as políticas de avaliação deixaram de ter a centralidade que tinham no Governo FHC, em que seus resultados embasavam a expansão do ensino pela via do setor privado. Os Governos Lula continuaram com a ampliação do acesso, mas priorizaram sua democratização, isto é, a inclusão de setores de menor renda, pardos e negros, indígenas e alunos de escolas públicas. Em que pese a ampliação das matrículas em instituições federais (universidades, institutos de tecnologia e UAB), o predomínio das matrículas no setor privado se manteve (75\%).

Houve a tentativa de criar um sistema de avaliação que resgatasse os princípios do
PAIUB, especialmente no primeiro Governo Lula, em que, como foi dito, o setor de professores ligados à ANDIFES e/ou ao PAIUB ocupou cargos na Secretaria de Educação Superior, no Inep e na CONAES, e pôde criar e começar a implantar o SINAES. No segundo Governo Lula, durante a gestão de Haddad, os professores das IFES foram perdendo influência na educação superior.

No meio do segundo governo, foram criados índices para a educação básica e para a educação superior, seguindo a tendência internacional de

18- Em 2011, o Enade seguiu algumas das mudanças postuladas na Portaria $n^{\circ}$ 40/2007, republicada em 2010. Por norma específica (Portaria n 8 , de 15 de abril de 2011, art. $5^{\circ}, \S 6^{\circ}$ ), os estudantes ingressantes foram dispensados da prova. A prova geral continuou sendo denominada Formação Geral. 
governar por indicadores. Mas, enquanto na educação básica o IDEB é utilizado para monitorar o desenvolvimento da educação e para definir regiões que receberão apoio do Ministério da Educação, na educação superior os índices são utilizados para regular o sistema. Na prática, apesar de as instituições federais estarem submetidas a esse sistema de regulação, ele exerce pouca influência, pois o desempenho dos alunos costuma ser maior que o mínimo exigido. Já para as IES privadas, resultados menores aos exigidos significam não apenas monitoramento via visitas de especialistas e eventuais compromissos de melhoria, mas também impedimentos para participação no Programa Universidade para Todos (PROUNI) e em solicitação de créditos junto ao BNDES. Ainda, os resultados acabam se tornando um selo de qualidade e são utilizados para marketing institucional. No final do governo Lula, os resultados aferidos pelos indices foram incorporados nas normativas de credenciamento e recredenciamento de IES e, especialmente, das universidades.

Em conclusão, embora em 2003, com a proposta da Comissão Especial de Avaliação - o SINAES e seus instrumentos de avaliação institucional e autoavaliação -, ensaiasse-se uma mudança radical nas práticas de avaliação da educação superior, no sentido de não deixar apenas o mercado regular o sistema, exercendo o próprio Ministério ações de supervisão, a partir de 2008 foi se recuperando com mais vigor a lógica do Governo FHC de ter um exame de larga escala como referência para a regulação do sistema.

\section{Referências}

AFONSO, Almerindo. Avaliação educacional: regulação e emancipação. 3. ed. São Paulo: Cortez, 2005.

ALMEIDA JUNIOR. Vicente de Paula. 0 processo de implementação das Comissões Próprias de Avaliação (CPAs): ações desenvolvidas e perfil dos coordenadores. In: RISTOFF, Dilvo; ALMEIDA JUNIOR, Vicente de Paula (Orgs.). Avaliação participativa: perspectivas e debates. Brasília: Inep, 2005.

ANDRIOLA, Wagner Bandeira; SOUZA, Laura Alves. Representações sociais dos gestores e dos técnicos das unidades acadêmicas da Universidade Federal do Ceará (UFC) acerca da autoavaliação institucional. Avaliação, Campinas; Sorocaba, v. 15, n. 2, p. 45-72, jul. 2010.

AUGUSTO, Rosana; BALZAN, Newton. A vez e a voz dos coordenadores das CPAs das IES de Campinas que integram o SINAES. Avaliação, Campinas; Sorocaba, v. 12, n. 4, p. 597-622, dez. 2007.

BARREYR0, Gladys Beatriz. De exames, rankings e mídia. Avaliação, Campinas; Sorocaba, v. 13, n. 3, p. 863-868, nov. 2008.

La educación superior en el primer gobierno de Lula da Silva en Brasil: políticas, actores y grupos participantes. Revista de la Educación Superior, v. 39, n. 153, p. 105-115, 2010.

BITTENCOURT, Hélio Radke; CASARTELLI, Alam de Oliveira; RODRIGUES, Alziro César de Morais. Sobre o índice geral de cursos (IGC). Avaliação, Campinas; Sorocaba, v. 14, n. 3, p. 667-682, nov. 2009.

BRASIL. Ministério da Educação. IDES: Índice de Desenvolvimento do Ensino Superior: a nova geração da avaliação do ensino superior brasileiro. Brasília: MEC, 2003a. (mimeo)

Presidência da República. Medida Provisória n 147, de 15 de dezembro de 2003. Institui o Sistema Nacional de Avaliação e Progresso do Ensino Superior e dispõe sobre a avaliação do ensino superior. Diário Oficial da União, Brasília, 16 dez. $2003 \mathrm{~b}$.

Ministério da Educação. Portaria Ministerial n².051, de 9 de julho de 2004. Regula os procedimentos de avaliação do Sistema Nacional de Avaliação da Educação Superior (SINAES). Diário Oficial da União, Brasília, 12 jul. 2004a.

Ministério da Educação. Instituto Nacional de Estudos e Pesquisas Educacionais Anísio Teixeira (Inep). Sistema Nacional de Avaliação da Educação Superior - SINAES: da concepção à regulamentação. 2. ed. ampl. Brasília: Inep, 2004 b. 
BRASIL. Ministério da Educação. Instituto Nacional de Estudos e Pesquisas Educacionais Anísio Teixeira (Inep). Comissão Nacional de Avaliação da Educação Superior (Conaes). Sistema Nacional de Avaliação da Educação Superior - SINAES: Roteiro de auto-avaliação institucional. Brasília: MEC/CONAES/SESU/ INEP, 2004c.

. Ministério da Educação. Instituto Nacional de Estudos e Pesquisas Educacionais Anísio Teixeira (Inep). Comissão Nacional de Avaliação da Educação Superior (Conaes). Diretrizes para a avaliação das instituições de educação superior. Braślia: MEC/CONAES/ INEP, 2004d.

. Presidência da República. Lei nº 10.861, de 14 de abril de 2004. Institui o Sistema Nacional de Avaliação da Educação Superior (SINAES) e dá outras providências. Diário Oficial da União, Brasília, 15 abr. 2004e.

. Ministério da Educação. Instituto Nacional de Estudos e Pesquisas Educacionais Anísio Teixeira (Inep). Comissão Nacional de Avaliação da Educação Superior (Conaes). Avaliação externa de instituições de educação superior: diretrizes e instrumento. Brasília, CONAES/INEP, 2005a. (versão preliminar)

. Ministério da Educação. Instituto Nacional de Estudos e Pesquisas Educacionais Anísio Teixeira (Inep). Comissão Nacional de Avaliação da Educação Superior (Conaes). Resolução n 1, de 11 de janeiro de 2005. Estabelece prazos e calendário para a avaliação das instituiç̧ões de educação superior. Diário Oficial da União, Braśilia, 21 jan. 2005b.

. Presidência da República. Decreto n 5.773, de 9 de maio de 2006. Dispõe sobre o exercício das funções de regulação, supervisão e avaliação de instituições de educação superior e cursos superiores de graduação e seqüenciais no sistema federal de ensino. Diário Oficial da União, Brasília, 10 maio 2006.

. Ministério da Educação. Portaria Normativa no 40, de 12 de dezembro de 2007. Institui o e-MEC, sistema eletrônico de

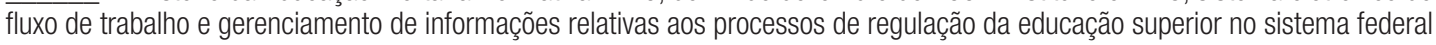
de educação. Diário Oficial da União, Brasília, 2007a.

. Presidência da República. Decreto nº 6.317, de 20 de dezembro de 2007. Aprova a Estrutura Regimental e 0 Quadro Demonstrativo dos Cargos em Comissão e das Funções Gratificadas do Instituto Nacional de Estudos e Pesquisas Educacionais Anísio Teixeira - INEP, e dá outras providências. Diário Oficial da União, Brasília, 21 dez. 2007b.

. Presidência da República. Decreto nº 6.904, de 24 de abril de 2007. Dispõe sobre a implementação do Plano de Metas Compromisso Todos pela Educação, pela União Federal, em regime de colaboração com Municípios, Distrito Federal e Estados, e a participação das famílias e da comunidade, mediante programas e ações de assistência técnica e financeira, visando a mobilização social pela melhoria da qualidade da educação básica. Diário Oficial da União, Brasília, 25 abr. 2007c.

. Ministério da Educação. Portaria Normativa nº 4, de 5 de agosto de 2008. Regulamenta a aplicação do conceito preliminar de cursos superiores, para fins dos processos de renovação de reconhecimento respectivos, no âmbito do ciclo avaliativo do SINAES instaurado pela Portaria Normativa 1 de 2007. Diário Oficial da União, Brasília, 2008a.

Ministério da Educação. Portaria Normativa no 12, de 5 de setembro de 2008. Institui o Índice Geral de Cursos da Instituição (sic) de Educação Superior. Diário Oficial da União, Brasilia, 2008b.

Ministério da Educação. Instituto Nacional de Estudos e Pesquisas Educacionais Anísio Teixeira (Inep). Cálculo do Conceito Preliminar de Cursos de Graduação: nota técnica. Diário Oficial da União, Brasília: Inep, 2008c.

Ministério da Educação. Secretaria de Ensino Superior. Supervisão especial dos cursos de pedagogia e normal superior: relatório de atualização dos processos. Abr. 2009a.

Ministério da Educação. Secretaria de Ensino Superior. Supervisão especial da composição de corpo docente de universidades e centros universitários: relatório parcial. Set. 2009b.

Conselho Nacional de Educação. Câmara da Educação Superior. Resolução nº 3, de 14 de outubro de 2010. Regulamento 0 Art. 52 da Lei n 9394 de 20 de dezembro de 1996 e dispõe sobre normas e procedimentos para credenciamento e recredenciamento de universidades do Sistema Federal de Ensino. Diário Oficial da União, Brasília, 15 de out. de 2010a.

. Ministério da Educação. Instituto Nacional de Estudos e Pesquisas Educacionais Anísio Teixeira (Inep). Comissão Nacional de Avaliação da Educação Superior (Conaes). Sistema Nacional de Avaliação da Educação Superior - SINAES: instrumento de avaliação institucional externa. Set. 2010b. Disponível em: <http://download.inep.gov.br/download/superior/institucional/2010/ instrumento_avaliacao_institucional_externa_recredenciamento.pdf>. Acesso em: 8 de set. 2011. 
BRASIL. Ministério da Educação. Portaria Normativa n 8, de 15 de abril de 2011. Diário Oficial da União, Braślia, 18 abr. $2011 a$.

Ministério da Educação. Instituto Nacional de Estudos e Pesquisas Educacionais Anísio Teixeira (Inep). Sistema Nacional da Avaliação da Educação Superior - SINAES: análise de relatórios de autoavaliação de Instituiç̧ões de educação superior. v. 3, Brasilia: Inep, 2011b.

BOTH, Ivo. Da avaliação precursora ao complemento da avaliação: PAIUB e SINAES construindo pontes. Avaliação, Campinas; Sorocaba, v. 10, n. 4, p. 61-73, dez. 2005.

CAPES (Coordenação de Aperfeiçoamento de Pessoal de Nivel Superior) Universidade aberta do Brasil: o que é? Disponível em: $<$ http://uab.capes.gov.br/index.php?option=com_content\&view=article\&id=6\&ltemid=18>. Acesso em: 17 de jan. 2012.

CARBONARI, Maria Elisa Ehrhardt. Programa de avaliação institucional: possibilidades, desafios e perspectivas. Avaliação, Campinas; Sorocaba, v. 11, n. 1, p. 87-101, mar. 2006.

CARVALHO, Cristina Helena Almeida. Uma análise crítica do financiamento do PROUNI: instrumento de estímulo à iniciativa privada e/ou democratização do acesso à educação superior? In: REUNIÃO ANUAL DA ANPED, 34., 2011, Natal. Anais... Natal, out. 2011. Disponivel em: <http://34reuniao.anped.org.br/images/trabalhos/GT11/GT11-935\%20int.pdf>. Acesso em: 17 de jan. 2012.

CASTRO, Claudio Moura. Quem entendeu a nova avaliação do ensino? Veja, ed. 2.079, 29 set. 2008.

CATANI, Afrânio Mendes; OLIVEIRA; João Ferreira. A reforma da educação superior no Brasil nos anos 90: diretrizes, bases e ações. In: CATANI, Afrânio Mendes; OLIVEIRA, Romualdo Portela de. Reformas educacionais em Portugal e no Brasil. Belo Horizonte: Autêntica, 2000. p. 95-135.

COLIGAÇÃO LULA PRESIDENTE. Uma escola do tamanho do Brasil: caderno temático do programa de governo. São Paulo: Comitê Lula Presidente, 2002.

CUNHA, Luiz Antônio. A educação superior no octênio FHC. Educação \& Sociedade, Campinas, v. 24, n. 82, p. 37-61, 2003.

DIAS SOBRINHO, José. Avaliação da educação superior. Petrópolis: Vozes, 2000.

Qualidade, avaliação: do SINAES a índices. Avaliação, Campinas; Sorocaba, v. 13, n. 3, p. 817-825, nov. 2008.

DIAS SOBRINHO, José; RISTOFF, Dilvo. Avaliação democrática: para uma universidade cidadã. Florianópolis: Insular, 2002.

DURHAM, Eunice. 0 modelo único é uma ilusão. 0 Estado de São Paulo, Aliás J3, 14 set. 2008.

FERNANDES, Ivanildo Ramos. 0 SINAES em sua vertente regulatória: sobre penas educativas e o controle do estado. Monografia (Conclusão do Curso Latino Americano de Políticas Públicas e Avaliação da Educação Superior - CLAEPPES) - Universidade Federal de Integração Latino Americana; Universidade Federal do Paraná, jul. 2010.

GIOLO, Jaime. "SINAES" intermitentes. Avaliação, Campinas; Sorocaba, v. 13, n. 3, p. 851-856, nov. 2008.

LEITE, Denise. Ameaças pós-rankings: sobrevivência das CPAS e da auto-avaliação. Avaliação, Campinas; Sorocaba, v. 13, n. 3 , p. 833-840, nov. 2008.

LIMANA, Amir. Desfazendo mitos: o que estão fazendo com o SINAES? Avaliação, Campinas; Sorocaba, v. 13, n. 3, p. 869-873, nov. 2008.

NEAVE, Guy. On the cultivation of quality, efficiency and enterprise: an overview of recent trends in higher education in Western Europe, 1986-1988. European Journal of Education, Oxford, v. 23, n. 1/2, p. 7-23, 1988.

PEIXOTO, Maria do Carmo Lacerda. Avaliação institucional externa no SINAES: considerações sobre a prática recente. Avaliação, Campinas; Sorocaba, v. 16, n. 1, p. 11-36, mar. 2011.

PINHO, Ângela. Ministério suspende vestibular de dois cursos de medicina. Folha de S. Paulo, Cotidiano C2, 5 dez. 2008.

POLIDORI, Marlis Morosini. Políticas de avaliação da educação superior brasileira: provão, SINAES, IDD, CPC, IGC e... outros índices. Avaliação, Campinas; Sorocaba, v. 14, n. 2 p. 439-452, jul. 2009.

POLIDORI, Marlis Morosini; FONSECA, Denise. Grosso; LARROSA, Sara Fernanda Tarter. Avaliação institucional participativa. Avaliação, Campinas; Sorocaba, v. 12, n. 2, p. 333-348 jun. 2007.

POLIDORI, Marlis Morosini et al. Políticas de avaliação da educação superior brasileira. Educação e Realidade, Porto Alegre, v. 36, n. 1, p. 253-278, jan./abr, 2011. 
PORTAL MEC. Cursos de direito com baixo desempenho passarão por supervisão. 26 set. 2007. Disponível em: <http:// www.portalmec.gov.br/index.php?option=com_content\&task=view\&id=9118>. Acesso em: 17 de jan. 2012.

. Especialistas opinarão sobre cursos. 11 fev. 2008a. Disponível em: <http: //200.130.3.30/index2.php?option=com_ content\&do_pdf=1\&id=9855>. Acesso em: 17 de jan. 2012.

Com menos vagas, cursos de direito sob supervisão pretendem melhorar o ensino. 27 ago. 2008b. Disponível em: <http://portal.mec.gov.br/index.php?option=com_content\&task=view\&id=11117>. Acesso em: 17 de jan. 2012.

ROTHEN, José Carlos; BARREYRO, Gladys Beatriz. Avaliação Agências e Especialistas: padrões oficiais de qualidade da educação superior. Ensaio, Rio de Janeiro, v. 17, p. 729-752, 2009.

Expansão da educação superior no Brasil e avaliação institucional: um estudo do Sistema Nacional de Avaliação da Educação Superior (SINAES) na Revista Avaliação. Série-Estudos (UCDB), v. 30, p. 70-77, 2010.

. Avaliação da educação superior no segundo governo Lula "provão II" ou a reedição de velhas práticas? Educação \& Sociedade, v. 32, n. 114, p. 21-38, jan./mar. 2011.

SAUL, Ana Maria. Avaliação emancipatória: desafio à teoria e à prática de avaliação e reformulação do currículo. São Paulo: Cortez, 1994.

SCHWARTZMAN, Simon 0 "conceito preliminar" e as boas práticas de avaliação do ensino superior. Revista da Associação Brasileira de Mantenedoras de Ensino Superior, n. 38, p. 9-32, dez. 2008.

SGUISSARDI, Valdemar. Reforma universitária no Brasil - 1995-2006: precária trajetória e incerto futuro. Educação \& Sociedade, Campinas, v. 27, n. 96, p. 1021-1056, out. 2006.

SILVA JÚNIOR, João dos Reis; SGUISSARDI, Valdemar. Novas faces da educação superior no Brasil: reforma do estado e mudanças na produção. 2. ed. São Paulo: Cortez, 2001.

TRINDADE, Hélgio (Org.). Universidade em ruínas: na república dos professores. Petrópolis: Vozes; Rio Grande do Sul: CIPEDES, 1999.

VERHINE, Robert Evan. Ajudando a entender a nova avaliação do ensino. 2008. Disponível em: <http://www.schwartzman.org. br/sitesimon/?p=797\&lang=pt-br>. Acesso em: 1 out. 2008.

Recebido em: 20.11.2012

Aprovado em: 27.06.2013

Gladys Beatriz Barreyro é doutora em Educação e professora da Escola de Artes, Ciências e Humanidades da Universidade de São Paulo (USP). Atua no Programa de Pós-Graduação em Educação e no Programa de Pós-Graduação em Integração da América Latina da USP. É também líder do Grupo de Estudos e Pesquisas em Políticas, História e Avaliação da Educação Superior (GEPPAHES).

José Carlos Rothen é professor do Departamento de Educação da Universidade Federal de São Carlos (UFSCar), onde atua no curso de Pedagogia e no Programa de Pós-Graduação em Educação. Edita o site <www.rothen.pro.br $>$ e é líder do Grupo de Estudos e Pesquisas em Políticas, História e Avaliação da Educação Superior (GEPPAHES) 